\title{
Técnica de SHIRA uma abordagem não convencional para exérese de mucocele: relato de caso
}

\section{SHIRA technique an unconventional approach to mucocele excision: case report}

\section{Técnica SHIRA un enfoque no convencional para la escisión de mucocele: reporte de caso}

\author{
Pamela Cassia Gomes \\ Wellington Luiz Vieira iD \\ Christian Recchioni iD \\ Rudiney Daruge (iD \\ Endereço para correspondência: \\ Pamela Cassia Gomes \\ Rua Perú, 27 \\ Vila Marabá \\ 68464-000 - Tucuruí - Pará - Brasil \\ E-mail: pamelacassia@hotmail.com
}

Recebido: 04.09.2020

Modificado: 07.09.2020

Aceito: 19.09.2020

\section{RESUMO}

Mucocele é uma lesão benigna pseudocística de retenção não neoplásica em glândulas salivares menores, comum em lábio inferior. Caracterizada pela ruptura do ducto glandular menor, ocorrendo extravasamento do muco ou saliva para o interior do tecido conjuntivo, de origem etiológicas diversas traumas ou inflamação de ducto salivar. Clinicamente nota-se lesão nodular de até $3 \mathrm{~cm}$, circunscrito, de coloração translúcida ou vermelho-azulada, indolor e flutuante à palpação, com maior prevalência em lábio inferior. A modalidade convencional de tratamento inclui exérese da lesão, criocirurgia, eletrocauterização, marsupialização, injeção de corticóide, agentes esclerosantes, ablação por laser tem sido explorado. Porém os métodos de tratamento ditados na literatura são baseados nas características da lesão e podem variar de cirúrgico a conservador. Este estudo tem por finalidade relatar um caso clínico em que o paciente foi submetido a remoção cirúrgica de mucocele, com eliminação imediata dos sinais e sintomas relatados pelo paciente, pela técnica de Shira. Uma técnica não convencional, simples, barata e segura; pois garante a remoção completa da lesão, prevenindo a recidiva. A cirurgia apresentou pós-operatório e cicatrização satisfatória.

PALAVRAS-CHAVE: Mucocele. Glândulas salivares menores. Patologia bucal.

\section{ABSTRACT}

Mucocele is a benign pseudocystic lesion with non-neoplastic retention in minor salivary glands, common in the lower lip. Characterized by the rupture of the minor glandular duct, with mucus or saliva leaking into the connective tissue, of various etiological origin, trauma or inflammation of the salivary duct. Clinically there is a nodular lesion of up to $3 \mathrm{~cm}$, circumscribed, 
translucent or bluish-red, painless and floating on palpation, with a higher prevalence in the lower lip. The conventional treatment modality includes excision of the lesion, cryosurgery, electrocauterization, marsupialization, injection corticosteroids, sclerosing agents, laser ablation has been explored. However, the treatment methods dictated in the literature are based on the characteristics of the lesion and can vary from surgical to conservative. The purpose of this study is to report a clinical case in which the patient underwent surgical removal of mucocele, with immediate elimination of the signs and symptoms reported by the patient, using the Shira technique. An unconventional, simple, inexpensive and safe technique; complete removal of the lesion, preventing recurrence. The surgery presented postoperative and satisfactory healing.

KEYWORDS: Mucocele. Salivary glands, minor. Pathology, oral.

\section{RESUMEN}

El mucocele es una lesión pseudoquística benigna con retención no neoplásica en glándulas salivales menores, frecuente en el labio inferior. Caracterizado por la rotura del conducto glandular menor, con fuga de moco a saliva al tejido conectivo, de origen etiológico diverso, traumatismo o inflamación del conducto salival. Clínicamente existe una lesión nodular de hasta 3 $\mathrm{cm}$, circunscrita, translúcida o rojo azulado, indolora y flotante a la palpación, con mayor prevalencia en el labio inferior. La modalidad de tratamiento convencional incluye exéresis de la lesión, criocirugía, electrocauterización, marsupialización, inyección de corticoides, agentes esclerosantes, se ha explorado la ablación con láser. Sin embargo, los métodos de tratamiento dictados en la literatura se basan en las características de la lesión y pueden variar de quirúrgico a conservador. Este estudio tiene como objetivo reportar un caso clínico en el cual el paciente fue sometido a la extirpación quirúrgica de mucocele, con eliminación inmediata de los signos y síntomas reportados por el paciente, mediante la técnica de Shira Una técnica poco convencional, simple, barata y segura; eliminación completa de la lesión, previniendo la recurrencia. La cirugía presentó una cicatrización postoperatoria y satisfactoria.

PALABRAS CLAVE: Mucocele. Glándulas salivales menores. Patología bucal. 


\section{INTRODUÇÃO}

Mucocele é uma lesão benigna pseudocística, desenvolve-se a partir do extravasamento ou retenção de muco, comum nas glândulas salivares menores, entre as localizações mais comuns, podemos citar mucosa interna do lábio inferior, assoalho de boca e ventre de língua, de origem traumática ou inflamatória ${ }^{1-4}$. Clinicamente as mucoceles são caracterizadas como lesões exofíticas, esféricas de aspecto nodular liso, circunscrito, submucoso, assintomático, podendo ser de coloração que varia de azulada para translúcida, variando de 0.3 a $1 \mathrm{~cm}$, sem predileção por sexo e idade ${ }^{2-6}$.

O diagnóstico é, muitas vezes, clínico, porém é aconselhável enviar a peça para o exame anátomo patológico, ao qual descreverá o achado histológico parede cística fibro-colágena, micrófagos espumosos, com muco extravasado, associado à infiltrado inflamatório misto de linfócitos, plasmócitos e neutrófilos ${ }^{5}$.

O tratamento adequado depende do tamanho, localização, podendo variar desde excisão cirúrgica, laserterapia, crioterapia, injeção de esteróides e micro-marsupialização, apresentando normalmente prognóstico favorável após exérese de lesão, com possibilidade de recorrência ${ }^{1-2}$.

Foi selecionada a técnica de Shira, proposta em 1962, pelo mesmo autor, indicada para mucoceles de grandes dimensões, é uma técnica segura que garante remoção completa da lesão evitando recidiva e consiste na aspiração do muco presente no interior da lesão seguida da injeção de um material hidrocolóide irreversível, conhecido popularmente como alginato ${ }^{6-8}$.

Nesse contexto, o objetivo deste trabalho é relatar o caso clínico de mucocele removido utilizando a técnica de Shira.

\section{RELATO DE CASO}

Paciente K.S.P, gênero feminino, leucoderma, 24 anos, compareceu ao Serviço de Cirurgia Bucomaxilofacial do Instituto da Face do AM, queixando de "uma bolha de cor transparente no lábio inferior" de aproximadamente dois meses de evolução, com história de traumas locais. Na anamnese, não relatou alteração sistêmica, nem qualquer hábito deletério. Ao exame clínico foi observado uma lesão nodular, mediando aproximadamente $1.2 \mathrm{~cm}$, com aspecto circunscrito, de coloração translúcida, indolor e flutuante à palpação em região de lábio inferior à direita, originada de traumas locais como hábito de mordida labial (Figura 1).

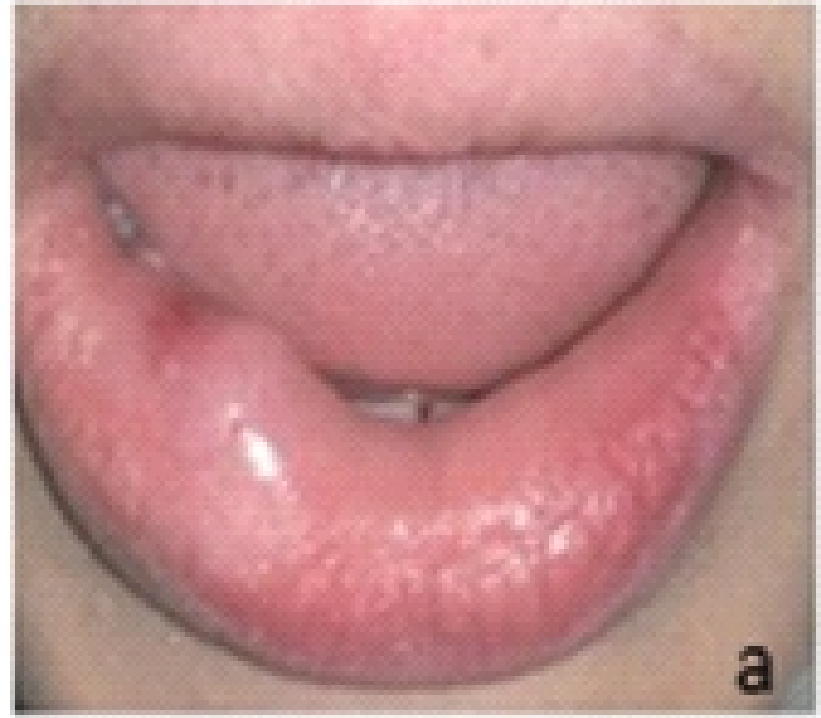

Figura 1 - Exame clínico de mucocele em lábio inferior.

O tratamento escolhido foi a remoção da mucocele pela Técnica de Shira, após anestesia local. A técnica de Shira, consiste na da punção aspirativa do conteúdo mucoso da lesão com uma seringa de Lue de $5 \mathrm{ml}$, introduzida lateralmente à lesão até o centro da lesão, sendo realizada a aspiração de $0.5 \mathrm{ml}$ de conteúdo líquido, desconectou-se a seringa Luer de $5 \mathrm{ml}$; contudo a agulha foi mantida em posição (Figura 2).

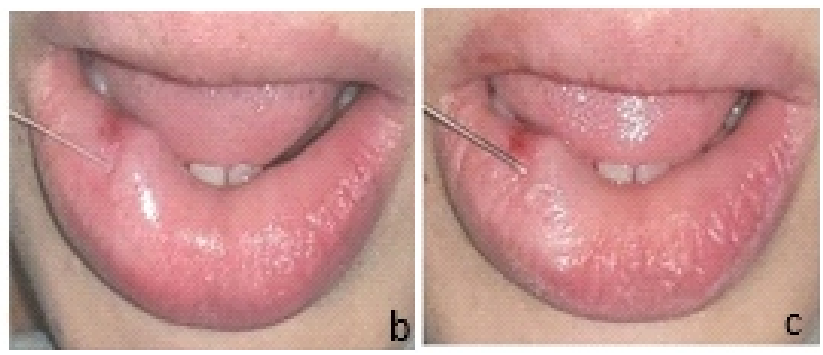

Figura 2 - Manobra de punção aspirativa em mucocele, e agulha se manteve em posição.

Manipulou-se o hidrocolóide irreversível (alginato) de forma que sua composição permanece mais líquida e fluida, na proporção de 3:1 de água e pó de forma a permitir que o material escora da seringa para preencher a lesão na mesma quantidade de líquido removido inicialmente da lesão $(0.5$ $\mathrm{ml}$ ), após encaixe da seringa na agulha que permaneceu na lesão após punção aspirativa (Figura 3). 


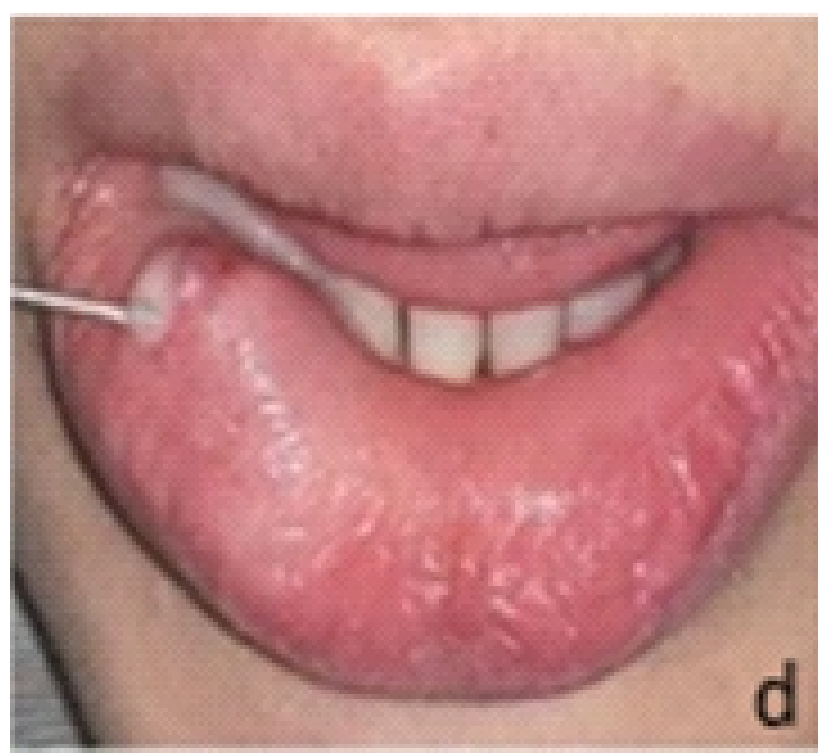

Figura 3 - Lesão sendo preenchida com hidrocolóide irreversível (alginato).

Após 8 minutos do tempo de "presa" do hidrocolóide irreversível (alginato), este apresenta consistência sólida (processo de geleificação), objetivando assim, a delimitação e facilidade para a excisão cirúrgica (Figura 4).

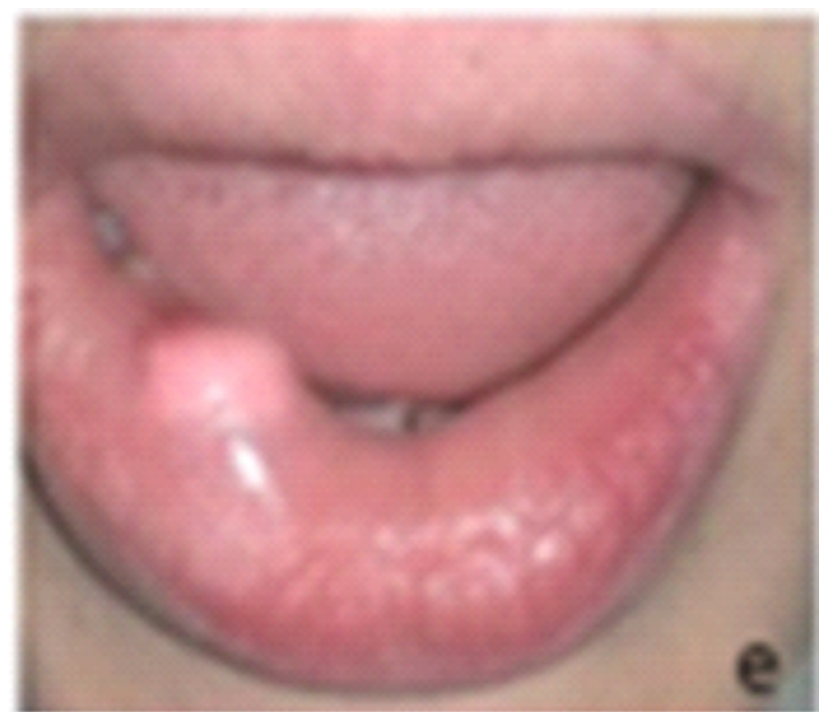

Figura 4 - Delimitação da lesão após presa do hidrocolóide (alginato).

Após delimitação da lesão realizou-se incisão cirúrgica linear de aproximadamente $1.5 \mathrm{~cm}$ com cabo de bisturi de Parker número 3 e lâmina fria de bisturi número 15; divulsão ao redor da lesão até sua total exposição com tesoura Iris ou Metzenbaum; após a exérese total da lesão, foram removidos os lóbulos das glândulas periféricas ao redor da cápsula; irrigação com solução de soro fisiológico $0.9 \%$ sobre a ferida; sutura simples com fio de nylon 3.0, peça cirúrgica foi armazenada em formol $10 \%$ e encaminhada para o exame anátomo patológico (Figura 5).
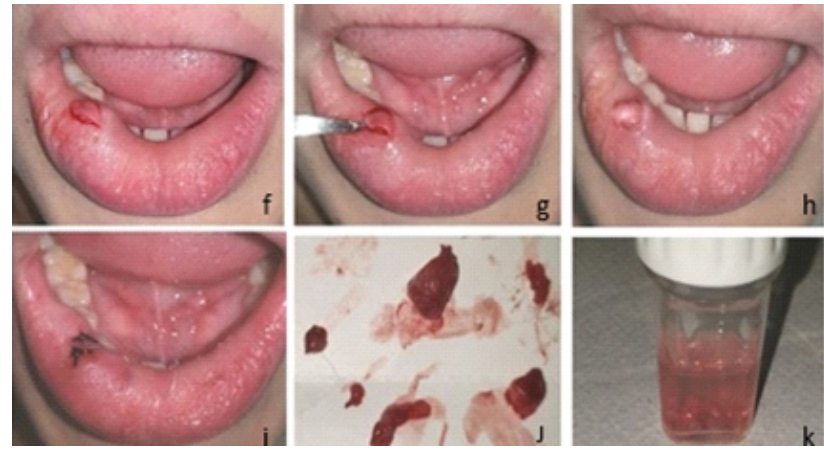

Figura 5 - Sequência de remoção da lesão, sutura nylon 3.0 e peça em formol $10 \%$ encaminhada para o exame histopatológico.

Paciente retornou 07 dias, após procedimento para remoção de sutura, sem queixas ou alterações, o resultado do exame histopatológico foi diagnóstico de mucocele de extravasamento (Figura 6).

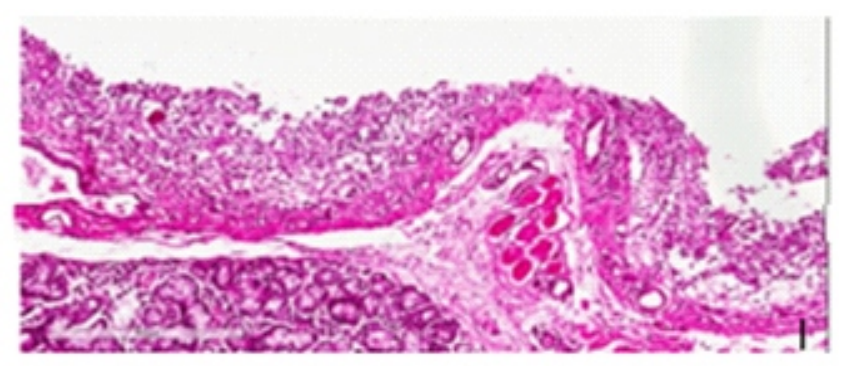

Figura 6 - Imagem histológica de lâmina da lesão.

\section{CONCLUSÃO}

A mucocele pode estar localizada em qualquer área da cavidade bucal, no entanto sua predileção maior é em lábio inferior. Independente da técnica terapêutica ou cirúrgica de escolha, deve-se remover toda lesão e glândulas menores acessórias. A técnica de Shira possui um diferencial, pela introdução de material hidrocolóide irreversível na lesão, ocasionando maior facilidade de manipulação e exérese total, diminuindo os índices de recidivas, no entanto, é necessário que haja cautela para que resíduos do material hidrocolóide irreversível (alginato), não infeccione a ferida cirúrgica. No caso acima descrito, a paciente apresentou prognóstico satisfatório, com boa cicatrização, ausência de infecções e estética satisfatória. 


\section{REFERÊNCIAS}

1. Bezerra TMM, Monteiro BVB, Henriques ACG, Carvalho MV, Nonaka CFW, Miguel MCC. Epidemiological survey of mucus extravasation phenomenon at an oral pathology referral center during a 43 year period. Braz J Otorhinolaryngol. 2016;82(5):536-42 .

2. Choi YJ, Byun JS, Choi JK, Jung JK. Identification of predictive variables for the recurrence of oral mucocele. Med Oral Patol Oral Cir Bucal. 2019;24(2):e231-5.

3. Liu JL, Zhang AQ, Jiang LC, Li KY, Liu FZ, Yuan DY, et al. The efficacy of polidocanol sclerotherapy in mucocele of the minor salivary gland. J Oral Pathol Med. 2018;47(9):895-9.

4. Titsinides S, Kalyvas D, Tosios K. Mucocele of the dorsal surface of the tongue: a case report. J Clin Exp Dent. 2018;10(5):e495-8.

5. Recchioni C, Silva MTB, Cabral LN. Doenças bucais de maior frequência na prática clínica. Prática em cirurgia bucomaxifacial. Belo Horizonte: Nativa; 2019.

6. Rebouças DS, Freitas DM, Costa TF, Farias TS, Pereira Junior FB, Assis AF. Tratamento de mucocele com emprego da técnica de Shira: relato de caso. Rev Odontol Bras Central. 2015;24(69).

7. Oliveira BF, Henrique DBB, Cruz JHA. Mucocele oral provocada por mordida acidental: relato de caso. Arch Health Invest. 2018;7(11).

8. Shira RB. Técnica simplificada para gestão de mucoceles e rânulas. J Oral Surg. 1962;20:374.

9. Abdel-Aziz M, Khalifa B, Nassar A, Kamel A, Naguib N, El-Tahan AR. Mucocele of the hard palate in children. Int J Pediatr Otorhinolaryngol. 2016;85:46-9.

10. Lucero RAC, Araceli GR, Cesar BFJ. Fenómeno de extravasación mucosa. Rev Tame. 2019;7(21):835-7.

11. Balan I, Camargo WR, Ribas MB, Navarro CH, Lobo F. Tratamento de mucocele com a técnica de Shira: relato de caso. Rev Odontol Araçatuba. 2019;40(2):54-8.

12. Prosdócimo ML, Agostini M, Romañach MJ, de Andrade BAB. A retros-pective analysis of oral and maxillofacial pathology in a pediatric population from Rio de Janeiro-Brazil over a 75-year period. Med Oral Patol Oral Cir Bucal. 2018;23(5):e511-7.

13. Zanotto PG. Levantamento dos casos de mucocele e rânula diagnosticados pelo laboratório de patologia bucal da Universidade Federal de Santa Catarina entre 2006 e 2018 [monograph]. Florianópolis (SC): Universidade Federal de Santa Catarina; 2019. 